\title{
Degeneration of Solventogenic Clostridium Caused by a Defect in NADH Generation
}

\author{
Shinsaku Hayashida and Sadazo Yoshino \\ Laboratory of Applied Microbiology, Department of \\ Agricultural Chemistry, Kyushu University 46, \\ Hakozaki, Fukuoka 812, Japan
}

Received August 8, 1989

\begin{abstract}
A degenerated strain of Clostridium saccharoperbutylacetonicum N1-4 ATCC13564 was isolated after 30 subcultures and was designated as DGN32. The product yields of DGN32 drastically decreased to below one-third of those of N1-4, but its acetone productivity remained the same as that of N1-4 when the culture pH was at 5.1. DGN32 with or without pH control evolved almost equimolar amounts of $\mathrm{CO}_{2}$ and $\mathrm{H}_{2}$ throughout the fermentation. The amount of $\mathrm{NADH}$ consumed for the acid and solvent production of DGN32 corresponded to that of NADH generated in the EMP pathway. These results suggested that the electron flow coupled with pyruvate metabolism to acetyl-CoA in DGN32 would be kept for $\mathrm{H}_{2}$ evolution, but not for $\mathrm{NADH}$ generation. However DGN32 cultivated with a redox dye (benzyl viologen) preferentially produced butanol though the butanol production rate was comparatively low. In DGN32 there was suppression of the NADH generation system coupled with pyruvate metabolism to acetyl-CoA, which could be essential for the metabolic transition from the acidogenic phase to the solventogenic phase.
\end{abstract}

A main characteristic of acetone-butanol fermentation is the metabolic transition from the acidogenic phase to the solventogenic phase, which correlate to the logarithmic phase and the stationary phase of growth, respectively. However, the regulatory mechanism of the metabolic transition is still poorly understood, though the acidic culture $\mathrm{pH},{ }^{1-4)}$ an undissociated form of butyric acid, ${ }^{3,5}$ ) and the availability and demand of ATP and $\mathrm{NADH}^{6-8)}$ were suggested as factors for the control of solvent production.

The degenerative process which is another characteristic of acetone-butanol fermentation has been frequently observed in repeated subcultures..$^{9-13)}$ The repeated subculturing of acetone-butanol-producing clostridia lead to degenerative changes which were manifested physiologically be lower sugar utilization and solvent production. Decrease of solvent production in the degenerated cell would involve regulatory aberration that would result in failure of the onset of the metabolic transition. ${ }^{13}$ ) George and Chen indicated the importance of elucidation of the degenerative processes for the breeding of acetone-butanol-producing clostridia, ${ }^{13)}$ but there has been no report suggesting that degeneration is a result of genetic aberration.

In this paper, we describe the characteristics of a degenerated strain isolated from a hyperbutanol-producer, C. saccharoperbutylacetonicum ATCC 13564, and discuss the metabolic features of the degenerated strain under the restoring conditions of solvent production that are considered to be important for the investigation of metabolic transition.

\section{Materials and Methods}

Bacterial strains and cultural conditions. Clostridium saccharoperbutylacetonicum N1-4 ATCC1356414) and its degenerated strain DGN32 were used throughout the work. N1-4 was purely reisolated as a single spore by a micromanipulator. DGN32 was isolated from the degenerated broth culture of strain N1-4 after 30 repeated subcultures in TYA medium. ${ }^{15)}$ Colonies of both strains were isolated on TYA agar plates, inoculated in $10 \mathrm{ml}$ of liquid TYA medium, and cultivated at $30^{\circ} \mathrm{C}$ for $24 \mathrm{hr}$. One 
$\mathrm{ml}$ of sterilized glycerin was added to the actively fermented broth and it was kept in liquid nitrogen until use. For measuring the fermentation products of both strains, one $\mathrm{ml}$ of the cell suspension kept in liquid nitrogen was inoculated in $9 \mathrm{ml}$ of fresh TYA medium and incubated for $24 \mathrm{hr}$ at $30^{\circ} \mathrm{C}$. One $\mathrm{ml}$ of the fermented broth was transferred to $9 \mathrm{ml}$ of fresh TYA medium and incubated at $30^{\circ} \mathrm{C}$ for $15 \mathrm{hr}$, and this was used as a subculture. $P G$ medium (potato, $150 \mathrm{~g}$; glucose, $10 \mathrm{~g}$; ammonium sulfate, $1 \mathrm{~g}$; calcium carbonate, $2 \mathrm{~g}$; tap water, $1000 \mathrm{ml}$ ) and synthetic medium described by Long et al ${ }^{16)}$ were used for the observation of spore formation.

Jar fermentation. Large scale fermentation was done to measure the yield of acids, solvents, $\mathrm{H}_{2}$, and $\mathrm{CO}_{2}$. One hundred fifty $\mathrm{ml}$ of the subculture was inoculated into a mini-jar fermentor (model M300, L. E. Marubishi Co., Ltd.) containing 31 of TYA medium under a stream of nitrogen gas, and incubated at $30^{\circ} \mathrm{C}$ with agitation at 60 rpm. The culture $\mathrm{pH}$ was monitored by a $\mathrm{pH}$ control unit (TOA) and adjusted to 5.1 by the addition of $1 \mathrm{~N} \mathrm{KOH}$. Broth was withdrawn periodically and cell turbidity, $\mathrm{pH}$, product yields, and residual sugar were measured as mentioned below.

Measurement of acid and solvent productions. Acid and solvent in the fermented broth were measured by gas-solid chromatography. ${ }^{17)}$ The gas chromatograph (Hitachi; type 163) was equipped with a column of Chromosorb 101 $(2 \mathrm{~m} \times 3 \mathrm{~mm})$. Analytical conditions were as follows: column teperature, $200^{\circ} \mathrm{C}$; injection temperature, $230^{\circ} \mathrm{C}$. The products were detected by FID. The yield of products was measured using isobutanol as an internal standard, and was recorded on Chromatopak C-R1A (Shimadzu Inc.).

Measurement of cell growth. Turbidity of the culture broth incubated in the test tube or of periodically sampled broth from the jar fermentor was measured with an electrophotometer (Tokyo Koden Ltd., Type 7A) at $\mathrm{OD}_{660 \mathrm{~nm}}$

Measurement of residual sugars. Glucose consumption during fermentation was measured by the residual glucose concentration. Residual sugar of the culture supernatant was measured by the glucose oxidase method, ${ }^{18}$ using the Glupase K kit (Katayama Pharmaceuticals Ltd.).

Measurement of fermentation gases. Fermentation gases were collected in a gas bag and the output volume was measured. The composition of the output gases was analyzed by gas chromatograph (Shimadzu GC 8A) equipped with a Porapack $Q$ and Molecular Sieve. The gases were detected by a thermal conductivity detector. Data was calculated on a Chromatopak C-R1A. The amount of gasses produced during intervals was calculated from concentrations and volumes of the output gases, according to the following equation.
Productivity of gas ( $\mathrm{mi} / \mathrm{hr} / \mathrm{l}$ broth)

$$
\begin{aligned}
= & \{[\text { (gas bag })+(\text { head space })+(\text { broth })]_{n} \\
& \left.-[(\text { head space })+(\text { broth })]_{n-1}\right\} t^{-1}
\end{aligned}
$$

$n$, times of sampling ( $n>0) ; t$, sampling interval (hr); gas bag, gas accumulated in gas bag; head space, gas accumulated in head space of bottle; broth, gas dissolved in broth culture.

\section{Results}

\section{Isolation of degenerated strain}

A colony of the wild type strain of Clostridium saccharoperbutylacetonicum NI-4 was inoculated in the TYA medium, and the vegatative cells in the early stationary phase were serially subcultured into $10 \mathrm{ml}$ of fresh TYA medium at 24-hr intervals. N1-4 has difficulty in forming spores in the TYA liquid medium, therefore, only vegetative cells would be transferred to a fresh TYA medium in each of the repeated subcultures. The residual culture broth was incubated for another $24 \mathrm{hr}$, and the products were assayed, as shown in Fig. 1. The yields of solvents remained high from the first to the 15th subculture. However it drastically decreased from the 16th subculture and reached a minimum in the following three subcultures. In co-culture of N1-4 and the degenerated strain, the amount of solvents only decreased when above $70 \%$ of the cell population was the degenerated strain (data not shown). The cocultivated N1-4 would assimilate the accumulated acids produced by the degenerated strain. This indicated that the degenerated strain gradually increased in the serial subculture and caused a degenerated culture when the population was above $70 \%$. The degenerated strain was isolated from the 30 th subculture on a TYA agar plate and was designated DGN32. The colony was transferred to fresh TYA medium and to other spore-forming media, but no spores were detected under microscopy. Then the isolated DGN32 was kept in liquid nitrogen and used throughout the following experiments. 


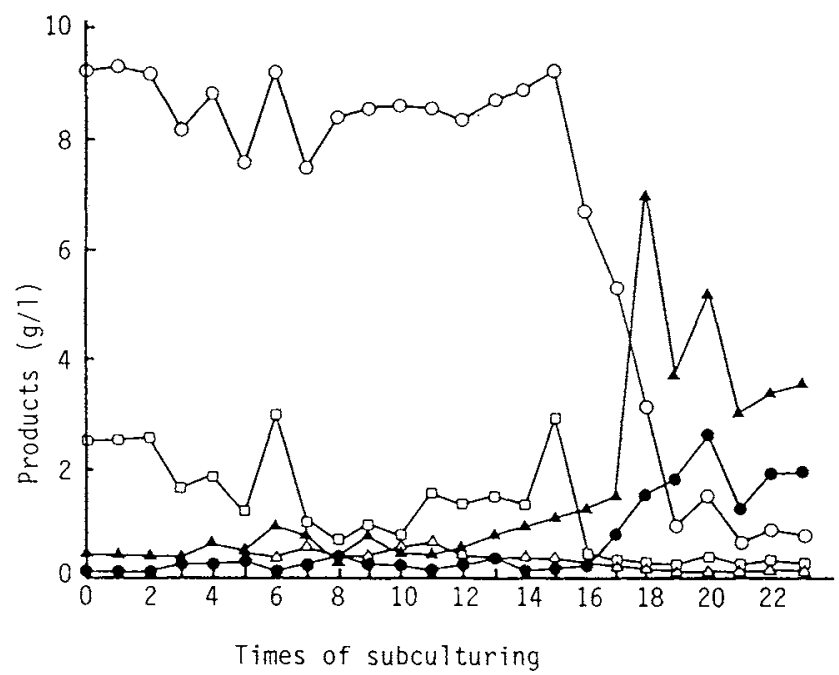

Fig. 1. Acid and Solvent Productions of Clostridium saccharoperbutylacetonicum N1-4 during Repeated Subculture.

$-\mathrm{O}-$, butanol; $-\square-$, acetone; $-\triangle-$, ethanol; $-\mathbf{\Delta -}$, acetate; $-\mathbf{-}-$, butyrate.

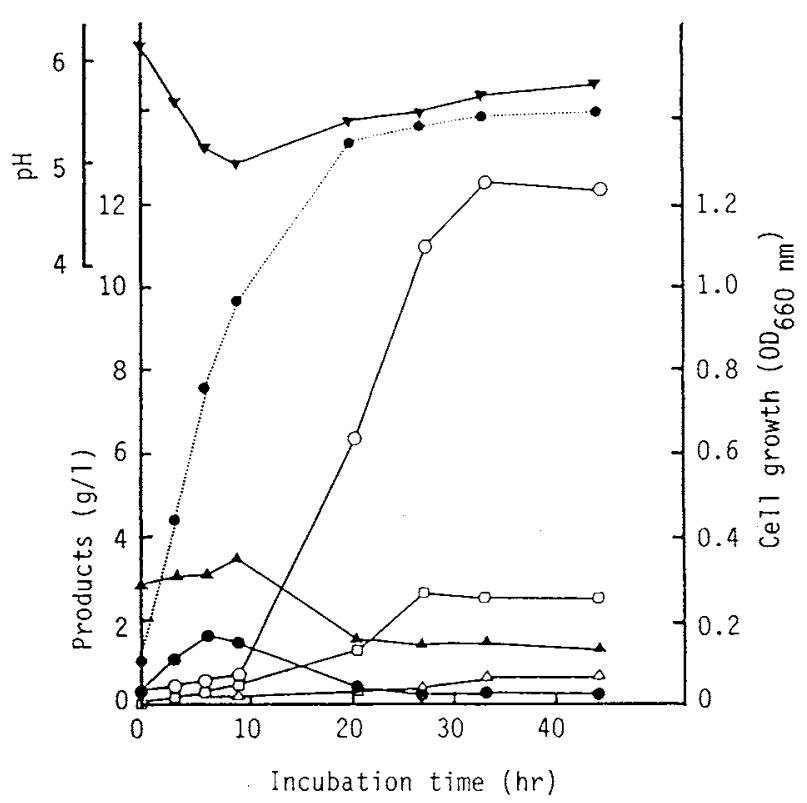

Fig. 2. Courses of Acid and Solvent Production of Clostridium saccharoperbutylacetonicum N I-4 (wild type strain).

$-\mathrm{O}-$, butanol; $-\square-$, acetone; $-\triangle-$, ethanol; $-\mathbf{\Delta -}$, acetate; $-\mathbf{-}$, butyrate; $-\boldsymbol{\nabla}-$, pH; --- ---, cell growth $\left(\mathrm{OD}_{660 \mathrm{~nm}}\right)$.

Decrease in solvent productivity of degenerated strain DGN32

The courses of acid and solvent productions of N1-4 and DGN32 are compared in Figs. 2 and 3. N1-4 clearly showed an acidogenic phase followed by a solventogenic phase, as typically observed in acetone-butanol fermentation. These distinctly separated acidogenic and solventogenic phases of products were correlated with the logarithmic and 


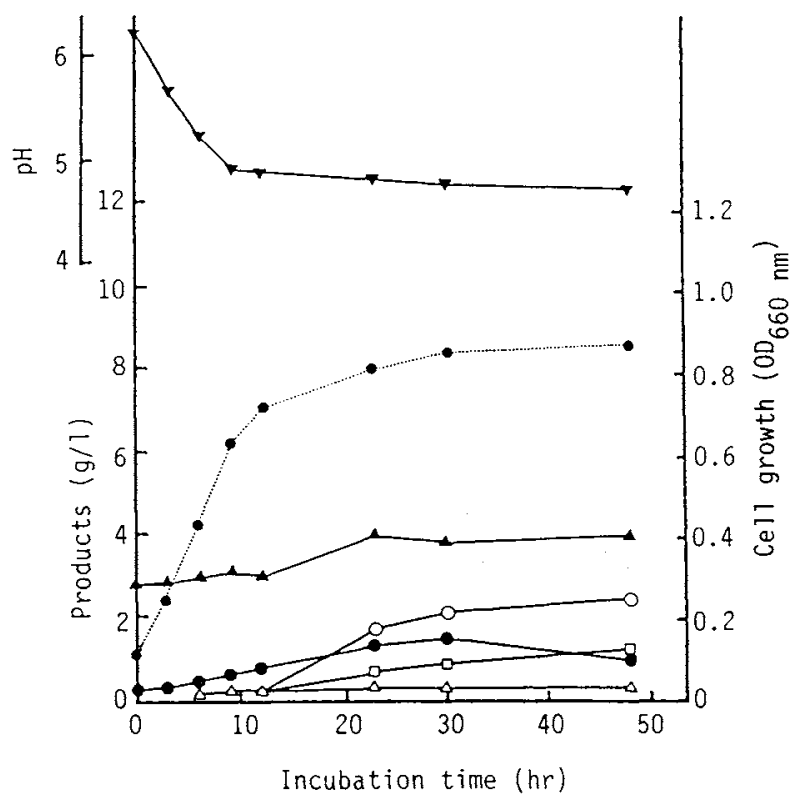

Fig. 3. Course of Acid and Solvent Production of Clostridium saccharoperbutylacetonicum DGN32 (degenerated strain).

$-\mathrm{O}-$, butanol; $-\square--$, acetone; $-\triangle-$, ethanol; $-\mathbf{-}-$, acetate; $-\bullet-$, butyrate; $-\boldsymbol{\nabla}-$, pH; $-\cdots--$, cell growth $\left(\mathrm{OD}_{660 \mathrm{~nm}}\right)$.

stationary phases of growth, respectively. The culture $\mathrm{pH}$ fell during the acidogenic phase and rose during the solventogenic phase accompanied by the assimilation of acids. The so-called "pH break" was usually observed at pH 5.0. On the contrary DGN32 did not show a distinct transition from the acidogenic phase to the solventogenic phase. The solvent productivity decreased as compared with that of N1-4 and acid assimilation was not observed. The logarithmic growth of DGN32 continued only for $9 \mathrm{hr}$ of cultivation and the cell growth ceased when the $\mathrm{OD}_{660 \mathrm{~nm}}$ reached 0.8 . No "pH break" was observed and the culture $\mathrm{pH}$ finally reached 4.6 when the fermentation ceased. DGN32 finally produced $3.6 \mathrm{~g} / \mathrm{l}$ of butanol and $1.5 \mathrm{~g} / \mathrm{l}$ of acetone after $120 \mathrm{hr}$ of cultivation. On the other hand, N1-4 produced $12.5 \mathrm{~g} / \mathrm{l}$ of butanol and $2.5 \mathrm{~g} / \mathrm{l}$ of acetone after only $36 \mathrm{hr}$ of cultivation. The percentage of consumed glucose in DGN32 was $60 \%$ but it reached $99.9 \%$ at $36 \mathrm{hr}$ of cultivation of N1-4.
Restoration of acetone productivity of degenerated strain DGN32 by controlling the culture $p H$

To reduce the response of the cells to acidic $\mathrm{pH}$, the culture was controlled at $\mathrm{pH} 5.1$ by the addition of $1 \mathrm{~N} \mathrm{KOH}$ as shown in Fig. 4. After $20 \mathrm{hr}$ of cultivation from the onset of $\mathrm{KOH}$ addition the culture $\mathrm{pH}$ spontaneously rose. Acids and solvents began to increase before the $\mathrm{pH}$ break. Butanol and acetone were finally produced at $8.1 \mathrm{~g} / \mathrm{l}$ and $6.1 \mathrm{~g} / 1$, respectively. The butanol and acetone productivity of DGN32 with the $\mathrm{pH}$ control was $0.19 \mathrm{~g} / \mathrm{l} / \mathrm{hr}$ and $0.14 \mathrm{~g} / 1 / \mathrm{hr}$, respectively. $\mathrm{Bu}$ tanol productivity was only one-third that of $\mathrm{N} 1-4(0.55 \mathrm{~g} / \mathrm{l} / \mathrm{hr})$, but the acetone productivity was almost the same as that of $\mathrm{Nl}-4$ $(0.14 \mathrm{~g} / \mathrm{l} / \mathrm{hr})$, as shown in Table 1 . The cell growth of DGN32 measured at $\mathrm{OD}_{660 \mathrm{~nm}}$ reached 1.15 . The actively fermenting culture were not due to the emergence of revertants from DGN32 to the wild type strain, because no cells withdrawn from the $\mathrm{pH}$ controlled 


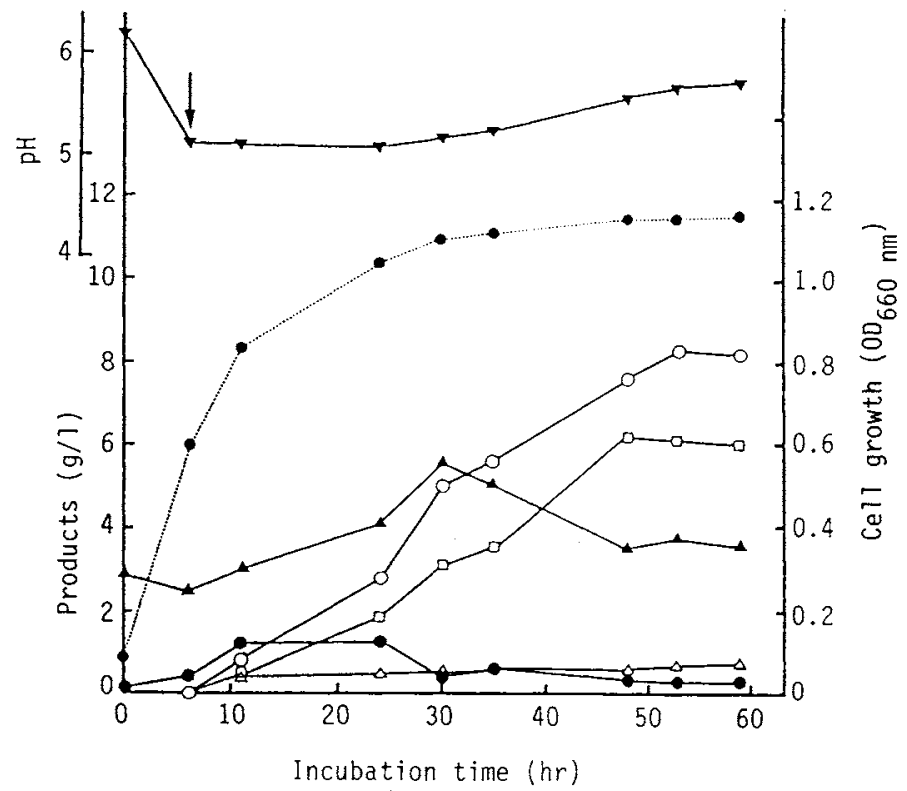

Fig. 4. Course of Acid and Solvent Production of Clostridium saccharoperbutylacetonicum DGN32 under Lower $\mathrm{pH}$ Control at 5.1.

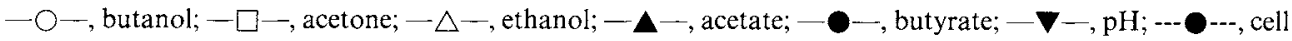
growth $\left(\mathrm{OD}_{660 \mathrm{~nm}}\right)$. Arrow indicates the start of $\mathrm{KOH}$ addition.

Table I. Productivity of Butanol and Acetone OF C. saccharoperbutylacetonicum N1-4 AND DeǴgnerated Strain DGN32

\begin{tabular}{lcc}
\hline \multirow{2}{*}{ Strains } & \multicolumn{2}{c}{$\begin{array}{c}\text { Production rate of solvents } \\
(\mathrm{g} / \mathrm{l} / \mathrm{hr})^{a}\end{array}$} \\
\cline { 2 - 3 } & Butanol & Acetone \\
\hline N1-4 & 0.56 & 0.14 \\
DGN32 (pH control) & 0.19 & 0.14 \\
DGN32 (+ BV) & 0.11 & 0.02 \\
\hline
\end{tabular}

a Production rate was calculated from the yields of solvents when the production was linear with time.

culture showed the restoration of solvent productivity in fresh TYA medium without $\mathrm{pH}$ control.

Effects of benzyl viologen on butanol production of degenerated strain DGN32

In DGN32 the acetone productivity but not butanol productivity was fully restored under $\mathrm{pH}$ control at 5.1. The difference in the butanol productivity between N1-4 and DGN32 suggested that the electron flow of
DGN32 would be altered from that of N1-4. Benzyl viologen (BV) is a redox dye that affects the electron flow in acetone-butanolproducing clostridia. ${ }^{19,20}$ ) Consequently, in DGN32 the yield of solvent increased when $6.25 \mu \mathrm{g} / \mathrm{ml}$ of $\mathrm{BV}$ was added to the culture. The courses of the acid and solvent production in the jar fermentor are shown in Fig. 5. The growth and the pH-fall in the BV-supplemented culture were slower than those of DGN32 with or without culture pH control, but the yield of butanol increased significantly and reached $10.5 \mathrm{~g} / 1$ at $120 \mathrm{hr}$ of cultivation. However the butanol productivity of DGN32 $(0.11 \mathrm{~g} / 1 / \mathrm{hr})$ was still lower than that of N1-4 $(0.55 \mathrm{~g} / \mathrm{l} / \mathrm{hr})$. The acetone productivity was suppressed to $0.02 \mathrm{~g} / 1 / \mathrm{hr}$ as shown in Table I and the final acetone yield was only $0.8 \mathrm{~g} / \mathrm{l}$.

\section{Gas production by degenerated strain}

The gas production of Clostridium is closely correlated with acid and solvent production. N1-4 produced equal volumes of $\mathrm{H}_{2}$ and $\mathrm{CO}_{2}$ until the mid-logarithmic phase as shown in Fig. 6(A). The $\mathrm{CO}_{2}$-productivity linearly in- 


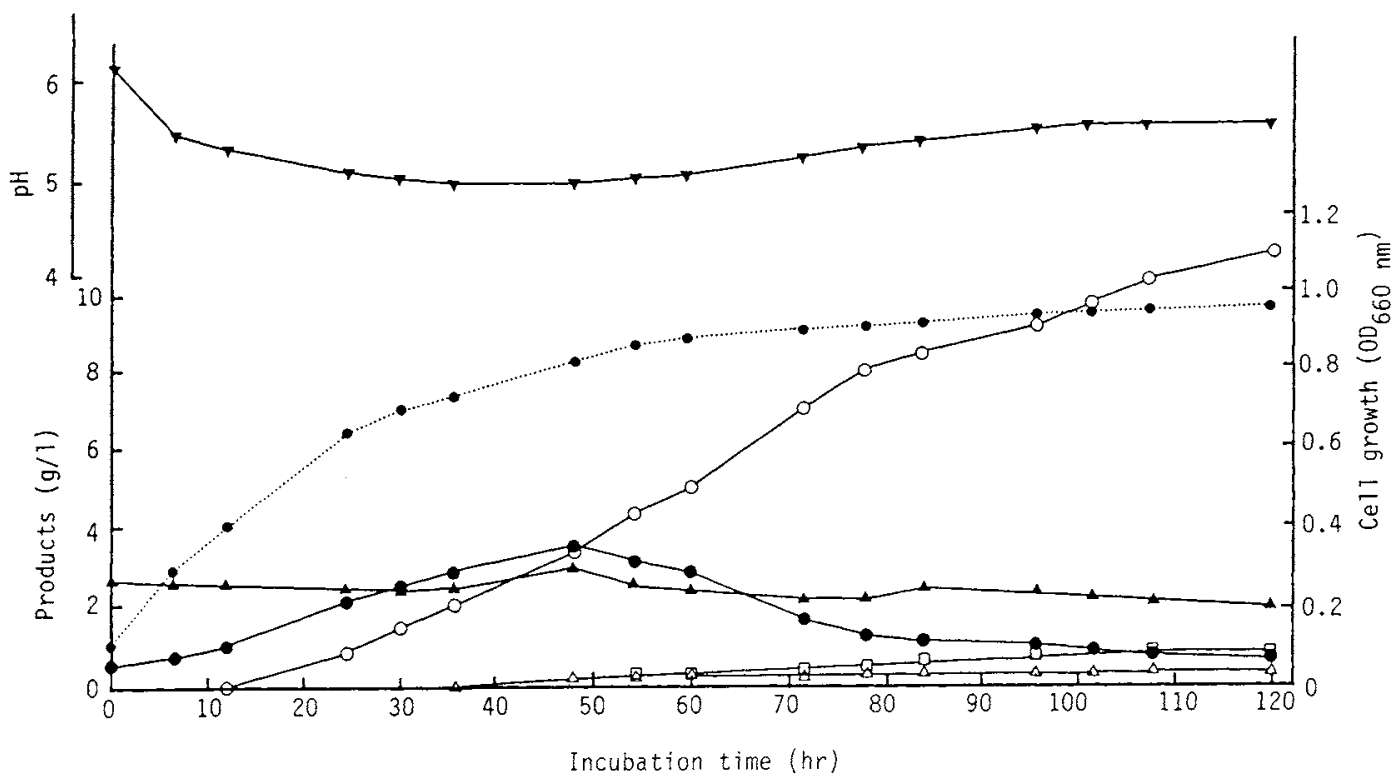

Fig. 5. Course of Acid and Solvent Production of Clostridium saccharoperbutylacetonicum DGN32 in the Existence of Benzyl Viologen.

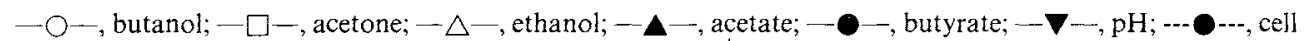
growth $\left(O D_{660 \mathrm{~nm}}\right)$.

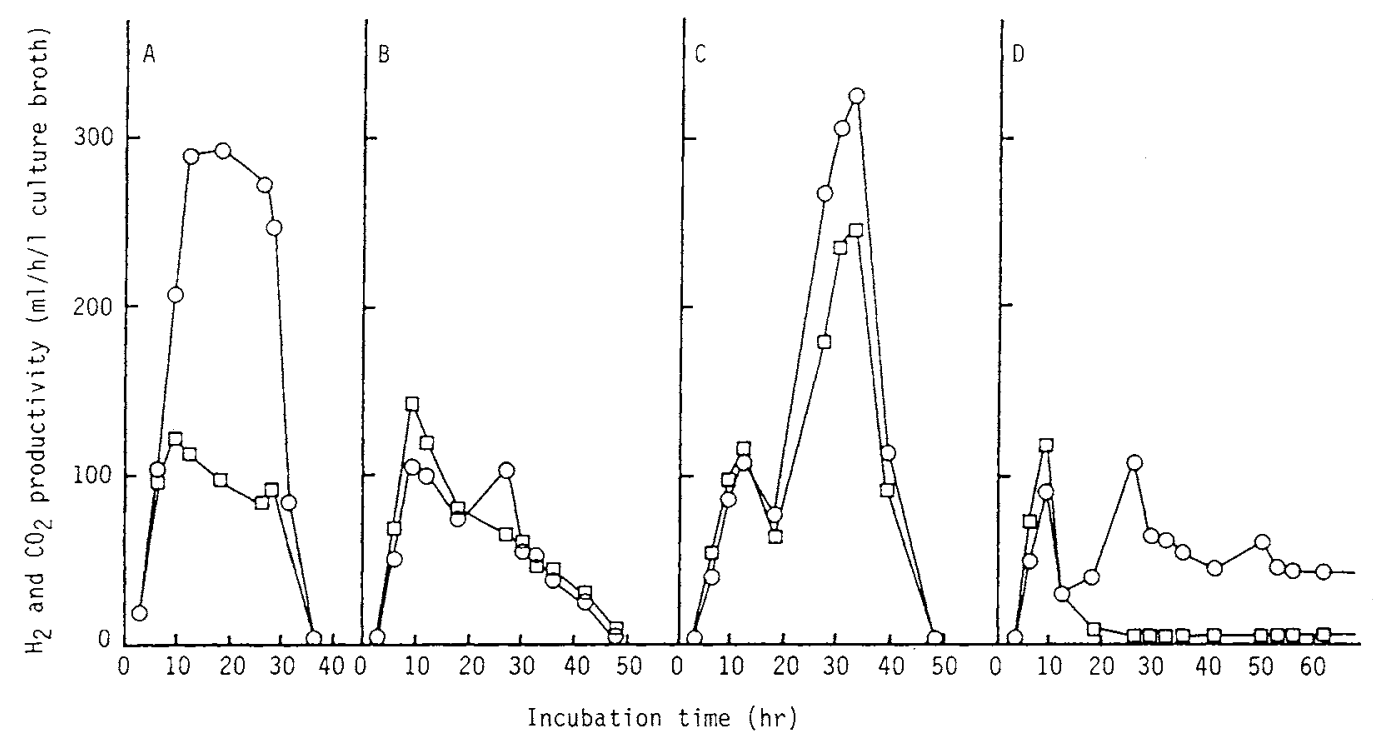

Fig. 6. Productivity of Hydrogen Gas and Carbon Dioxide of Clostridium saccharoperbutylacetonicum N1-4, and DGN32 with or without pH Control.

(A), strain N1-4; (B), strain DGN32; (C), strain DGN32 under pH control; (D), strain DGN32 in the presence of benzyl viologen; $-\square-, \mathrm{H}_{2} ;-\mathrm{O}-, \mathrm{CO}_{2}$.

creased and reached a maximum at the $\mathrm{pH}$ break. However the $\mathrm{H}_{2}$ productivity increased until the mid-logarithmic phase. During the solventogenic phase after the $\mathrm{pH}$ break N1-4 produced two to three times as much $\mathrm{CO}_{2}$ as $\mathrm{H}_{2}$. 
Table II. Products of FERmentation of Glucose by Clostridium saccharoperbutylacetonicum Strain N1-4, and Degenerated Strain DGN32 under pH Control AND IN THE PRESENCE OF BV

\begin{tabular}{|c|c|c|c|c|}
\hline \multirow{2}{*}{ Products strain } & \multicolumn{4}{|c|}{ Yield $^{a}$} \\
\hline & N1-4 & DGN32 & DGN32/pH 5.1 & DGN32/BV \\
\hline Butyrate & 0.8 & 24.9 & 0.5 & 3.7 \\
\hline Acetate $^{b}$ & -7.0 & 33.9 & 13.8 & -2.7 \\
\hline $\mathrm{CO}_{2}{ }^{c}$ & $209.1(222.5)$ & $202.3(223.1)$ & $247.8(268.8)$ & $176.2(194.9)$ \\
\hline $\mathrm{H}_{2}^{d}$ & $65.6(69.2)$ & $183.7(197.6)$ & $196.8(224.2)$ & $28.7(32.0)$ \\
\hline Ethanol & 6.9 & 3.4 & 5.1 & 5.9 \\
\hline Butanol & 79.9 & 38.0 & 51.1 & 80.9 \\
\hline Acetone & 20.4 & 20.0 & 48.9 & 7.5 \\
\hline $\mathrm{NADH}^{e}$ & $(335.0)$ & $(208.6)$ & $(215.6)$ & $(342.8)$ \\
\hline
\end{tabular}

a mol/100 mol of glucose fermented.

${ }^{b}$ TYA medium contains $3 \mathrm{~g}$ of ammonium acetate as an ingredient.

$c$ Values in the parentheses were calculated from following equation: $\mathrm{mol}$ of $\mathrm{CO}_{2}=2$ (mol of butyrate + butanol $)+3(\mathrm{~mol}$ of acetone $)+(\mathrm{mol}$ of acetate + ethanol $)$.

$d$ Values in the parentheses were calculated from following equation: $\mathrm{mol}$ of $\mathrm{H}_{2}=[4(\mathrm{~mol}$ of butyrate + butanol + acetone $)+2(\mathrm{~mol}$ of acetate + ethanol $)]-\left(\mathrm{mol}\right.$ of $\left.\mathrm{NADH}^{d}\right)$.

$e$ Values in the parentheses were calculated from the following equation: $\operatorname{mol}$ of $\mathrm{NADH}=2(\mathrm{~mol}$ of butyrate $)+2(\mathrm{~mol}$ of ethanol $)+4(\mathrm{~mol}$ of butanol $)$.

In contrast, $\mathrm{H}_{2}$-productivity of DGN32 coincided with the $\mathrm{CO}_{2}$ productivity throughout the fermentation, though more $\mathrm{H}_{2}$ than $\mathrm{CO}_{2}$ was produced during the logarithmic phase as shown in Fig. 6(B). The productivities of $\mathrm{H}_{2}$ and $\mathrm{CO}_{2}$ reached maxima at $9 \mathrm{hr}$ of cultivation and then gradually decreased. The courses of production of gas in the $\mathrm{pH}$ controlled culture were similar to those of DGN32 without pH control until $20 \mathrm{hr}$ of cultivation as shown in Fig. 6(B) and (C). However, $\mathrm{H}_{2}$ and $\mathrm{CO}_{2}$ productivities of DGN32 in the $\mathrm{pH}$-controlled culture increased after $20 \mathrm{hr}$ of incubation though the productivity of $\mathrm{CO}_{2}$ was slightly higher than that of $\mathrm{H}_{2}$, parallel with the increasing acetone production. The $\mathrm{H}_{2}$ evolution of DGN32 cultured with BV drastically decreased, and it was negligible after $20 \mathrm{hr}$ of cultivation, as shown in Fig. 6(D). The low productivity of $\mathrm{H}_{2}$ reflected the hyper-production of butanol against acetone.

\section{Estimation of $\mathrm{CO}_{2}, \mathrm{H}_{2} \mathrm{NADH}$}

The yield of the end products reflects whether the electron flow is directed to NADH

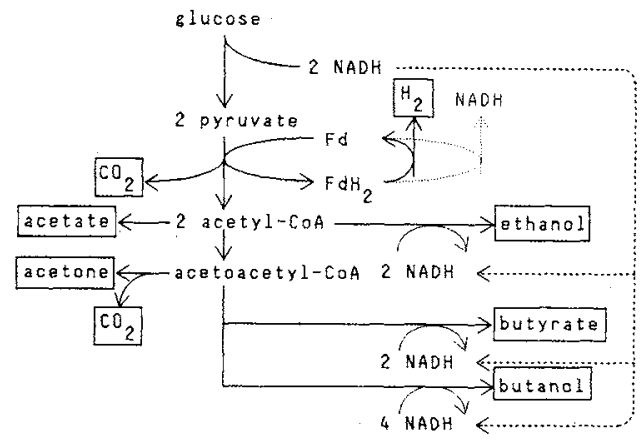

Fig. 7. Proposed Metabolic Pathway of Degenerated Strain DGN32.

generation or to $\mathrm{H}_{2}$ evolution, since $4 \mathrm{~mol}$ of $\mathrm{NADH}$ are consumed for one mole of butanol synthesis but no NADH is consumed for acetone synthesis. DGN32 produced equimolar amounts of butanol and acetone under pH control, but N1-4 produced four times as much butanol as acetone in moles, as shown in Table II. And DGN32 evolved almost the same molar $\mathrm{CO}_{2}$ with $\mathrm{H}_{2}$, but $\mathrm{N} 1-4$ evolved three times more $\mathrm{CO}_{2}$ than $\mathrm{H}_{2}$. These estimated amounts of $\mathrm{H}_{2}$ and $\mathrm{CO}_{2}$ from the yield of acids and solvents agreed with the experimental data on the output of gasses. More- 
over, DGN32 only generated $215.6 \mathrm{~mol}$ and $208.6 \mathrm{~mol}$ of $\mathrm{NADH}$ in the pH-controlled and $\mathrm{pH}$ uncontrolled cultures, respectively, but $\mathrm{Nl}-4$ generated $335 \mathrm{~mol}$ of NADH from $100 \mathrm{~mol}$ of glucose. The amount of NADH generated by DGN32 during fermentation was the same as that generated in the EMP pathway. Therefore the electron flow of DGN32 coupled with pyruvate metabolism to acetyl-CoA, that is catalyzed by pyruvate-ferredoxin oxido-reductase, could be only directed to the $\mathrm{H}_{2}$ evolution but not directed to the NADH generation, as shown in Fig. 7. On the contrary, DGN32 preferably produced butanol upon the addition of $\mathrm{BV}$ and the amount of $\mathrm{NADH}$ generated was more than that of N1-4. However, the productivity of butanol was not restored to the level of N1-4 by $\mathrm{BV}$ addition.

\section{Discussion}

The electron flow of DGN32 was thought to be different from that of N1-4. The constant production of equimolar of $\mathrm{CO}_{2}$ and $\mathrm{H}_{2}$ in DGN32 suggested that the electron flow did not change throughout the fermentation. Moreover, as shown in Table 2, DGN32 with or without $\mathrm{pH}$ control only consumed an amount of NADH equimolar with that generated in the EMP pathway, because the acetone-butanol-producing clostridia generated $2 \mathrm{~mol}$ of NADH in the EMP pathway, and $2 \mathrm{~mol}$ of $\mathrm{NADH}$ and/or $\mathrm{H}_{2}$ in total via pyruvate metabolism from one mole of glucose, as shown in Fig. 7. These results indicated that hydrogen generated via the pyruvate metabolism is only consumed for $\mathrm{H}_{2}$ evolution but not for NADH generation throughout the fermentation. Moreover, they suggested that DGN32 would have aberration(s) in the regulatory mechanism of metabolic transition that enhanced the $\mathrm{H}_{2}$ production. On the other hand, in DGN32 with benzyl viologen the yield of butanol was restored though the production rate was compratively low. Benzyl viologen is known to be an artificial electron acceptor of hydrogenases, and the resulting reduced $\mathrm{BV}$ probably acted a role as an electron donor in $\mathrm{NAD}^{+}$reduction, ${ }^{21)}$ and it consequently suppressed $\mathrm{H}_{2}$ productivity. The restoration of butanol production suggested that the NADH generation system via pyruvate metabolism would be partially preserved in DGN32, though it was supposed to be suppressed without an electron acceptor like benzyl viologen.

In a following report, we would like to describe the correlation of NADH generation with solvent production at the enzyme level.

Acknowledgments. This work was supported in part by a Grant-in-Aid for Scientific Research from the Ministry of Education, Science and Culture of Japan

\section{References}

1) M. Gottwald and G. Gottschalk, Arch. Microbiol., 143, 42 (1985).

2) L. Huang, L. N. Gibbins and C. W. Forsberg, Appl. Environ. Microbiol., 50, 1042 (1985).

3) F. Monot, J. M. Engasser and H. Petitdemange, Biotechnol. Bioeng. Symp., 13, 207 (1983).

4) J. W. Roos, J. K. McLaughlin and E. T. Papoutsakis, Biotechnol. Bioeng., 27, 681 (1984)

5) J. R. Martin, H. Putitdemange, J. Ballongue and R. Gay, Biotechnol. Lett., 5, 89 (1983).

6) R. Datta and J. G. Zeikus, Appl. Environ. Microbiol., 9, $522(1985)$.

7) B. H. Kim, P. Bellows, R. Datta and J. G. Zeikus, Appl. Environ. Microbiol., 8, 764 (1984)

8) C. L. Meyer and E. T. Papoutsakis, Appl. Microbiol. Biotechnol., 24, 159 (1986).

9) A. Kutzenok and M. Aschner, J. Bacteriol., 64, 829 (1952).

10) J. R. Gapes, V. F. Larsen and I. S. Maddox, J. Appl. Bacteriol., 55, 363 (1983).

11) B. Meinecke, H. Bahl and G. Gottschalk, Appl. Environ. Microbiol., 48, 1064 (1984).

12) M. G. N. Hartmanis, H. Ahlman and S. Gatenbeck, Appl. Microbiol. Biotechnol., 23, 369 (1986).

13) H. A. George and J.-S. Chen, Appl. Environ. Microbiol., 46, 321 (1983).

14) S. Ogata, S. Yoshino, S. Okuma and S. Hayashida, $J$. Gen. Microbiol., 28, 293 (1982).

15) S. Ogata, K. Fujino, S. Yoshino, S. Hayashida and K. Yuita, J. Gen. Appl. Microbiol., 32, 101 (1986).

16) S. Long, D. T. Jones and D. R. Woods, Appl. Environ. Microbiol, 45, 1389 (1983).

17) F. Monot, J.-R. Martin, H. Petitdemange and R. Gay, Appl. Environ. Microbiol., 44, 1318 (1982).

18) H. U. Bermeyer and E. Berut, "Methods of 
Enzymatic Analysis," ed. by H. U. Bergmeyer, 20) T.-S. Kim and B.-H. Kim, Biotechnol. Lett., 10, 123 Academic Press, New York, 1963, p. 123. (1988)

19) G. Rao and R. Mutharasan, Biotechnol. Lett., 8, $893 \quad$ 21) M. Shin and D. I. Arnon, J. Biol. Chem., 240, 1405 (1986). (1965). 